\title{
The trend of software cost estimation in Ethiopia Case study: Addis Ababa
}

\author{
Asebe Teka Nega \\ Wolkite university, collage of informatics and computing, wolkite ,Ethiopia
}

\begin{abstract}
-
For a different item, you can purchase. There are different costs to purchase that you can analysis the benefit and loses, even if on the software it has different approaches to analysis their wages, the developer company can get their analysis by the different methods. There are a lot of software cost estimation methods are appearing in different years but still, those methods have their own drawback on making a correct effort and scheduling estimation, here in the paper Today there are different software cost estimation methods that the software company uses from the requirement to implementation phase. Corrected cost estimation supports us to complete the project on planned times and budgets. This paper is mainly presenting the current situations of cost estimation on software placed in Addis Abeba's different software compony
\end{abstract}

\section{Keyword: - software cost estimation}

\section{Introduction}

Software cost estimation is estimating the effort and schedule estimation [1], and it may be referred to as resource valuation [2], software estimation [3], or project estimation [4] in literature. It is a vital software management action and is the basis for project bidding, budgeting, planning, and cost control. The study of Software cost estimation started as early as the 1960s [2]. There are several means and models that the software business uses for the software cost estimate, in a developed country because of their availability and well trend experts, they are very confused which software cost estimation methods and models are used for very software project but the opposite is true in Addis Ababa as I try to see some software company. All methods and models have their strengths and weakness in cost estimation, so it is very difficult to decide which one is better from others. Till now there is no software cost estimation model or method to incorporate all things that Developer Company needs. To solve this type of problem it is very necessary to know about the software cost estimation methods and models. Cost estimation is one of the most difficult tasks in project management. It is to accurately estimate the needed resources and required schedules for software development projects. This all estimation process includes estimating the size of software, effort, the schedule and the whole cost that is needed for developing the software, [5], having this all process the cost estimation model or technique must be accurate or at least near to the reality. All cost estimation models or technique have their drawbacks based on the above criteria that is why for improvement purposes at a different time there evolving new cost estimation method or model. In the last decades ' research, there are many software cost estimation methods including algorithmic methods, estimating by analogy, expert judgment method, price to win method, top-down method, and bottom-up method. No one method is necessarily good or bad to the other, in fact, their strengths and weaknesses are often complementary to each other. To understand their strengths and weaknesses is very important when you want to estimate your project. For improving the accuracy of cost estimation different cost estimation models are developed among these, COCOMO can be referred to as an example. One of the most important indicators which should be noticed is the size of the project. The estimation of effort and cost be contingent on the correct prediction of the size. Generally, the effort and cost estimations are hard in software development. The reason is that software projects are often not unique and there is no background or previous experience with them. Therefore, the prediction seems complicated. On the side, production in such projects is not concrete so the measurement of effort, cost and the amount of 
development in the software project are very difficult. In addition, the requirements of the software projects are changing continuously which will cause the changing of the prediction. Because of the above problems, project managers usually try to avoid using cost or effort guesstimates or at least do the estimations at a limited domain. Describing the tradition and importance of the estimation methods with their effect on the project success looks necessary in the software projects so that the software project managers are ensured of their usage. Inaccuracy in the software cost and effort estimation via optimistic or pessimistic prediction causes a problems in the software projects having the above very detail knowledge about the software cost estimation, as I see there are many software companies especially in Addis Ababa, that all to estimate the software cost estimation, the most problem is that to estimate the software cost when there is biding, they only for the computation there may be overestimation or underestimation they know all about after they finish their works..

\section{Background}

There are different software cost estimation methods those cost estimations have their advantage and disadvantages

\section{$\checkmark$ The 2CEE cost estimation model}

It is 21st Century Effort Estimation it is also a first model combining software engineering with the data mining techniques. It is both for software cost models and an effort estimation tool. It uses a difference in data mining and machine learning methods such as a nearest neighbor, feature subset selection, bootstrapping local calibration to propose the most accurate software cost model. 2CEE uses leave-one-out cross-validation as a measure of model performance [6].

\section{$\checkmark$ Expert Judgment Method}

It is the most useful method for software cost estimation. To know the effort of somebody on your software company you can monitor them over time, or you can accelerate the process by asking them about a topic they are passionate about.

$\checkmark$ Estimating by Analogy

Different cost estimation models have been developed with analogy methods. Estimation with Analogy means it is based on the actual values achieved within the organization in the previous and identical project is better indicators and predict the future project performance much better than the new starts from scratch. Actual data from the completed projects are extrapolated to estimate the proposed project. This method can be used either at the system level or at the component-level. Estimating by analogy is relatively straightforward. it has alitile similarity with expert judgment since experts often search for analogous situations so as to inform their opinion.

\section{$\checkmark$ Algorithmic Method}

The first cost estimation model generates by using the algorithmic method, this shows the importance of the algorithm-based model in the files of software cost estimation. This method mostly uses equations to perform software estimates. The equations are derived from historical data by performing research like a Source Lines of Code (SLOC), different functions to perform, language, design methodology, skill-levels, risk assessments, etc. this method is designed to come with mathematical equations to perform software cost estimation. there are different models developed with algorithm methods, such as COCOMO models, the Putnam model, and function points-based models $[5,7]$.

$\checkmark$ COCOMO Models

the Constructive Cost Model (COCOMO) is commonly used to estimate software costs. This model is a very simple form $[5,8]$ : MAN-MONTHS $=\mathrm{K} 1 *$ (Thousands of Delivered Source Instructions) K2 Where K1 and $\mathrm{K} 2$ are two parameters dependent on the application and development environment. COCOMO model estimation is precise in an account that concerning characteristics of the software to be developed, different qualified expertise in a development team, and the software development environment. Some of these factors are:

The complexity of the software

Required reliability

Size of database

Required efficiency (memory and execution time)

Analyst and programmer capability 
Experience of the team in the application area

Experience of the team with the programming language and computer

Use of tools

In software engineering practices many of these factors affect the person months required by an order of magnitude or more. this model assumes that requirement is already defined in an early stage that the requirements are stable. This is often not the case [9]. it is a regression model. this model was functioned with 63 different projects selected. The primary input is KDSI. The first version of the COCOMO model was originally developed in 1981 . The newest version, COCOMO 2.0, was developed. this new version estimation model is a tailorable family of software size models, involving object points, function points and source lines of code; nonlinear models for software reuse and reengineering; an exponent-driver approach for modeling relative software diseconomies of scale; and several additions, deletions, and updates to previous COCOMO effort-multiplier cost drivers.

\section{$\checkmark$ Putnam model}

Larry Putnam of Quantitative Software Measurement developed the Software Life-cycle Model (SLIM) in the late 1970s [10]. based on Putnam's life -cycle we called SLIM as d Rayleigh distribution of project personnel level versus time. It can work with source instructions, ballpark techniques, function points, which are the most popular size estimating methods.and also to estimate one's project effort, defect rate, and schedule. Technology Constant or Productivity factor (PF) and a Manpower Buildup Index (MBI)are used to influence the shape of the curve. Software Life-cycle Model by using previously completed project data they can analyze and record data then used to calibrate the model, to get values of MBI and PF we set different questions to be answered from the existing database. In Software Life-cycle Model, Productivity is used to link the basic Rayleigh manpower distribution model to the software development characteristics of size and technology factors.

\section{$\checkmark$ AGILE COCOMO MODEL}

There is a lot of cost estimation model developed by using the base of the COCOMO model. Agile
COCOMO model in one of them. A COCOMO ${ }^{\mathrm{TM}}$ tool that is very easy to use and simple to learn. It uses within the addition of the full COCOMO and used for analogy-based estimation to generate accurate results for a new project.

\section{$\checkmark$ SEER-SEM}

SEER-SEM is a product offered by Galorath, Inc. of El Segundo, California This model is based on the original Jensen model [11] and has been on the market some 15 years. During that time it has evolved into a sophisticated tool supporting topdown and bottom-up estimation methodologies. Its modeling equations are proprietary, but they take a parametric approach to estimation. The scope of the model is wide. It passes through all software project development phases from requrmet specification , design, development, delivery, and maintenance. It handles a variety of environmental and application configurations, such as client-server, standalone, distributed, graphics, etc. It models the most widely used development methods

\section{$\checkmark$ SELECT estimator}

SELECT estimator by SELECT Software Tools is part of a suite of integrated products designed for component-based development modeling. It is designed for large scale distributed systems development. It is object oriented that this model is used to estimate software costs based on business objects and components. its inputs allow the model to be used at any phase of the software development life-cycle, most significantly even at the feasibility stage when little-detailed project information is known.

As I try to explain the different software cost estimation methods, there some related topics that are related to my questioners.

\section{The Accuracy Of Software Cost Estimation}

Whatever you choose those methods no estimation be perfect, from different studies [12, 13] have surveyed the accuracy of effort and schedule estimation. The results of these survey showed that $59 \%-76 \%$ projects were completed overestimated effort and 35\%-80\% were over schedule. Most of the previous effort overrun reported is between $18 \%$ and $41 \%$, and the mean schedule overrun is between $22 \%$ and $25 \%[12,13]$.on those software company, after a deal with the organization they asked to other signature because of they give a different reason. This is because from the scratches they do not know 
detail about the project and they are not given the price on truly and confident requirement because they have not real cost estimation model. And the project manager, have not any knowledge about cost estimation .on most software company there are few programmers but no other discipline that the team, the designer, the requirement gatherer, and different teams are not involved because of different factor they give., the other those software company have not different specialized worker like network, database, software, etc. .If they get those specialists from the market, they are forced to pay more money, but the company will have good form and it acts as a Software Company rather than a stock market.

\section{The Choice Of Estimation Method}

From the above different software cost estimation method we can say that selecting a correct estimation is a very difficult task. If we do any minor mistakes for this work, the result is high financial loss and completion of project time is increased. It is common that we apply different software cost estimations methods for software development life cycle. It says in [14] that most company's used analogy or expert judgment to make estimations, and very few projects (14\%-26\%) used model-based estimation methods. The model-based methods include formal estimation models such as COCOMO, Use-Case-based estimation, FPA-metrics or other algorithm-driven methods. Even if they are not knowing what kind of methods they use (that most companies do not know even what the cost estimation models), are. they see only their benefit like they calculate numbers of worker and their monthly salary and some external factors like if there is office renting and so on, then they give money especially for binding purpose, the readymade software is also available but most are work customizing and they work with web developments, without calculating detail they ask only the final cost to the customers. This may make the company owners give more time for the money not the quality of work that the subject follows.

\section{For What Purposes Are Cost Estimations Used}

It is discussed in the literature [20] that software cost estimation can be used for a number of purposes, e.g. budgeting, tradeoff and risk analysis, project planning and control, and software process improvement analysis. Different usage purposes of estimation may require different properties of estimation methods and can produce different values for organizations. When software cost estimations are used for the software life cycle different cost models are used to have good transparency. Most of those software companies do not collect sufficient data for doing software estimation especially when there is binding and also if there is a standalone application. Researchers prove this that, organizations feel uncomfortable to use models they do not fully understand, etc. no scholars are trying to define why model-based methods are not used extensively but they try to look up its purpose of usage for project planning and scheduling. However, the previous surveys have not addressed usage purposes such as software process improvement analysis or short-term project planning.

\section{The Importance Of Software Cost}

This is to improve the cost estimation methods, Software Company's in Addis most are not understanding for what purpose they use cost estimation, that even the importance of the selection It is very important to know that institutions are satsfide with the current software cost estimation. If organizations are satisfied with the software cost estimation, they will have fewer incentives to improve the estimation methods and process; and if organizations are dissatisfied, they can invest more to improve the software cost estimation.

\section{When Do Organizations Usually Make Cost Estimations?}

As project lifecycle proceeds, one institutions usually have a different amount of information for software cost estimation and may apply different estimation technologies at different development phases. It is illustrated in [1] that the uncertainty ranges of cost estimations present a decreasing trend as the software development proceeds. Looking different background I try to define the following queasiness for those software company in Addis these are mainly on software size, effort, schedule, defect, I try to see 10 software company on job site and make interview with some workers and discussions based on the following questions and finally I try to show some effort and schedule estimation using COCOMO models as case study

* What is the accuracy of effort and schedule estimation and have the effort distributed on each discipline?

* How is your workflow?

* What are the different estimation methods used?

* Does project size affect effort and schedule 
estimation accuracy?

For what purposes are cost estimations used?

What are the causes of inaccurate estimations?

- If you are not using any kind of cost estimation model what are the barriers and difficulties in the application of software cost estimation models?

\section{Results And Analysis}

W What is the accuracy of effort and schedule estimation and have the effort distributed on each discipline?

As early I mention there are a lot of factors that determine the cost estimations from these are numbers of workers and qualities of workers even if you have more workers without having quality and competent performance workers the company may put under quotation. from my questions, 4 companies have well-subjected combinations worker that they work on their worker interest and excel on that particulars area but 6 of them are they have a few workers and those workers are work here and there that they all rotate by the managers when some software development occurs they are not calculate mummers of labor need they only give the order to do the software. Labors with different disciplines and experiences are very important for estimation. Most software companies finish their work with more delay they agreed to the organization because of different internal as well as external factors. Except the software already made by the company them self or customized from others source, there is a delay, as shown in table 1 clearly there is no accuracy on the most project.

\section{How is your workflow?}

In the software discipline, there is its own workflow from the requirement to an implementation phase. Having good understanding on each phase has a great advantage on cost estimation that if they establish all necessary software teams the workflow is good but if not overall work is missed from those software company's only 3 have well-organized team but others have not such organized team one worker may work all things from the requirement to implementation phase which if there is anything new updating or maintenance on the system the worker must be there and all operation is understood by this king only on that specific project if he is not the company loos its work and break with its different customers.

What are the different estimation methods used?

It is essential to note that organizations may use a combination of two or more different methods. The estimation methods reported can be classified into four categories: expert judgments, analogy, capacityrelated or price-to-win methods, and model-based methods. The capacity related methods regard software cost estimation as the capacity and directly take the person or schedule's constraints as estimates. price-to-win also has some constraints, e.g. customer's cost and schedule budgets, as estimates. The model-based methods include formal estimation models such as COCOMO, Use-Casebased estimation, FPA-metrics or other algorithmdriven methods. From my interview 7 of them uses expertise judgment and 1 use COCOMO and 2 of them use analog method except for one company they are not now with the term what kind of methods are they used to estimate.

What are the causes of inaccurate estimations?

Differ software company's respond this question giving different reasons as I try to clarify on the dalliance $f$ duration there are internal as well as external factors from those reasons are, the company owners are not discussed for all related workers on cost estimation issues, there is no on-job training, not enough resources for estimation, lake of stockholders collaboration, full time engages of developers, the project binding requires pre-defined the project cost, requirement may be volatiles, business pattern of the company, lack of training and appropriate applications of estimation methods and so on.

* If you are not using any kind of cost estimation model what are the barriers and difficulties in the application of software cost estimation models?

By default, they use one or two software cost estimation model but not the famous one witch is COCOMO 2 model, except 1 company which is used cocomo 2 the others use either expert or analog they use.

The main thing they issue is the company run for business as it is profitable it calculates all 
extravagancy for making the profit and, after making analysis they give the cost.

\section{Summary And Discussion}

I try to identify areas of potential improvement, and try to provide suggestions on how to improve the software cost estimation methods. Related to the current situation of cost estimation that I make the interview on Software Company I have the following observations:

Software companies that try to work the software projects suffered from effort or cost overruns.

Large software projects had lower effort and schedule estimation accuracy was more prone to effort and schedule overruns and had a higher variance of estimation accuracy than small projects.

Computing managers and professionals were neither particularly satisfied nor dissatisfied with the software cost estimation. That indicates that managers or professionals do not have much desire to introduce new cost estimation methods

> A company usually made cost estimations at early phases of the software development lifecycle. Especially when they have biding. But in meantime, they modify it coming with different reasons

These software companies are building their beginning with good bases as the country is developing in all aspect including the software industry there may are a lot of challenges.

\section{As My View}

If they need to be good software company competent they have to restructure their workflow. as they correct workflow they become hire different specialists from the market even if this is also some head-ack to find from the market

When they compete in biding rather they fix the software cost at an earlier stage they should wait at least they finish the design phase that is may another challenges negotiation with the organization.

if yet they are not using software cost estimation or if they use expert or analog method they have to change their cost estimation to currently well-known software cost estimation model that is COCOMO2 even if it is difficult to estimate a line of code but when we work on it for more time it becomes perfect. It is best which nearly the same accuracy of effort and schedule is. I also use one case study for project $\mathrm{x}$ that's I got from interview which is work with COCOMO model that I try to show how COCOMO calculate the effort and the duration, and all the data I found from the software company for 1 projects I explain detail with the Table 1 what the use to work each project like line of code, duration, total birr (NOTE:- these projects, are already finished and implemented )

\section{A Case Study On Project $X$}

History data use for estimating

The current trend on government organization for application developer which have 0-6 year experience has with range of (low, medium, high ) 6000 birr monthly which around 72000 birrs annually paid then Low is the salary paid at the 25th percentile of all respondents in this dataset; Median is the 50th percentile; high is the 75th percentile.

Definition: - software development designs, requirement specifies, coding, tests, debugs, maintains, and documents computer programs. It may work with and modify packaged applications. and also works with users to support business activities. It uses for users to identify problems and design integrated solutions. Since 3 of the members of this project are not experienced in Java, among 8 team members I will apply a $-20 \%$ correction to the median salary. according to historical data from the above, the estimated labor rate per person-month will be

$((72,000 / 12)(0.80+0.80+0.8+1+1+1+1+1)) /$ 8 birr » 5430 birr

\section{LOC-Based Estimation}

estimation shown below is based on n "best-effort" estimation from previous programming experiences and existing software size. The line of code for this project is 3600 .

The cost estimates for LOC are with COCOMO formula for effort and duration

Estimation. The COCOMO model is used, for which

\section{Effort $\mathrm{E}=\mathrm{a}$ KLOC $\mathrm{b}$}

- Duration $\mathrm{D}=\mathrm{c} \mathrm{E} d$

The project is classified as an organic project, using default values $\mathrm{a}=2.4, \mathrm{~b}=1.05, \mathrm{c}=$

2.5 And $d=0.38$.

$\mathrm{E}=2.4(\mathrm{KLOC}) 1.05$

$=2.4(3.6) 1.05$

$\gg 9$ person-months 
$\mathrm{D}=2.5 \mathrm{E} 0.38=$

2.5(9) 0.38

»5.8 months

$\mathrm{N}=\mathrm{E} / \mathrm{D}$

$=9 / 5.8=1.56$

$\gg 2$

Above results indicate that for two staff members; it will take 5.8 months to finish the project. Since we have 8 team members, the project duration should be shorter. Our best-effort estimation for the project duration because of the additional team member is 8 months. Based on that calculation, the estimated project cost will be 5430 birr x 8 × 8 » 347520 birr By using this COCOMO model the budget for each phase as follows

Fig 1:- comparison between the estimated software's with COCOMO estimation

\begin{tabular}{|c|c|c|c|c|c|c|c|c|c|}
\hline $\begin{array}{l}\text { Proj } \\
\text { ect } \\
\text { nam } \\
e\end{array}$ & Lime of code & $\begin{array}{l}\text { Project } \\
\text { type }\end{array}$ & $\begin{array}{l}\text { perso } \\
\text { nt they } \\
\text { have }\end{array}$ & $\begin{array}{l}\text { Dura } \\
\text { tion } \\
\text { they } \\
\text { ask }\end{array}$ & $\begin{array}{l}\text { Total } \\
\text { birr they } \\
\text { estimate }\end{array}$ & $\begin{array}{l}\text { Person } \\
\text { with } \\
\text { COCO } \\
\text { MO }\end{array}$ & $\begin{array}{l}\text { Durati } \\
\text { on } \\
\text { with } \\
\text { COCO } \\
\text { MO }\end{array}$ & $\begin{array}{l}\text { Histor" } \\
\text { y data }\end{array}$ & $\begin{array}{l}\text { Cost } \\
\text { estimatio } \\
\text { nby } \\
\text { COCO } \\
\text { MO }\end{array}$ \\
\hline$X$ & 3600 & Organics & 8 & 13 & 215950 & 9 & 5.8 & 5430 & 347520 \\
\hline
\end{tabular}

\section{Reference}

[1] Beohm, B.W. 1981. Software Engineering Economics.Prentice

[2] Briand and Wieczorek, L.C. 2002. Resource estimation in software engineering.

[3] Moløkken, K., Jørgensen, M., Tanilkan, S.S., H, Gallis, Lien, A.C. and Hove, S.E. 2004. A survey of software estimation in the Norwegian industry. In Proceedings of the 10th International Symposium on Software Metrics.

[4] Wydenbach, G. and Paynter, J. 1995. Software Project Estimation: a Survey of Practices in New Zealand. New Zealand

[5] COCOMO II Model definition manual", version 1.4, University of Southern California.

[6] Jairus Hihn, Karen Lum "2CEE, A TWENTY FIRST CENTURY EFFORT ESTIMATION METHODOLOGY" Lane Dept. CSEE West Virginia University ISPA / SCEA 2009

[7] Oscar Marbán, Antonio de Amescua, Juan J. Cuadrado, Luis García "A cost model to estimate the effort of data mining projects
[8] Z. Oscar Marbán, Antonio de Amescua, Juan J. Cuadrado, Luis García, "Cost Drivers of a Parametric Cost Estimation Model for Data Mining Projects"

[9] Caper Jones., "Estimating software cost" Tata Mc- Graw -Hill Edition 2007.

[10] Putnam, L. and W. Myers (1992), Measures for Excellence, Yourdon Press Computing Series.

[11] Jensen R. (1983),"An Improved Macrolevel Software Development Resource Estimation Model

[12] Phan, D. 1990. Information Systems Project Management: an Integrated Resource Planning Perspective Model, in the Department of Management and Information Systems. Arizona: Tucson.

[13] Sauer, C. and Cuthbertson, C. 2003. The State of IT Project Management in the UK 2002 2003. Templeton College, University of Oxford.

[14] MCAULAY, K. 1987. INFORMATION SYSTEMS DEVELOPMENT AND THE CHANGING ROLE OF MIS IN THE Organisation. FIRST NEW ZEALAND MIS MANAGEMENT CONFERENCE, WELLINGTON 